\title{
Educación, pobreza y delincuencia: ¿nexos de la violencia en México?
}

\author{
Education, Poverty and Crime: \\ Links of Violence in Mexico?
}

\author{
Henio Millán-Valenzuela (D) https://orcid.org/0000-0003-0115-0636 \\ ElColegio Mexiquense A.C., México,hmillan@cmq.edu.mx
}

Eduardo Pérez-Archundia (D) https://orcid.org/0000-0003-2685-7347

Instituto Superior de Ciencias de la Educación del Estado de México, México, eperarc@hotmail.com

Recepción:

26/06/18

Aprobación:

$15 / 10 / 18$

\begin{abstract}
The goal is to analyze the influence of poverty and education on crime, especially on the recent wave of violence in Mexico. The methodology used consists in ten lineal regression models, which proceed in a deductive way, up to when determination coefficient does not increase. Results point out that influence is indirect in the case of violent crime; and direct, in the rest of cases. In both, crime prevails when certain low threshold of poverty and high level of educational are reached. First conclusion: the rent-extraction model of political management imposes these conditions; this way, it sets up an administrated impunity. Second: when the State becomes weak and loses control, owing to power dispersion and neo-liberal policies, impunity becomes generalized and loses its administrated character. This way violent crime is unlashed.
\end{abstract}

Key words: education, poverty, crime, violence, Mexico.

Resumen: El objetivo es examinar la influencia de la pobreza y la educación sobre la delincuencia, especialmente en la reciente ola de violencia en México. La metodología consiste en diez modelos de regresión lineal, que se suceden en forma deductiva, hasta que el coeficiente de determinación no aumenta. Los resultados indican que la influencia es indirecta en el caso de los delitos violentos, y directa, en el resto de los del fuero común. En ambos casos, la delincuencia se impone con ciertos umbrales bajos de pobreza y altos del promedio de escolaridad. Primera conclusión: este condicionamiento es suministrado por el modelo rentista de gestión política, que instala una impunidad administrada; y segunda: cuando el Estado se debilita y pierde el control, debido a la dispersión del poder y las políticas neoliberales, la impunidad se generaliza y pierde su carácter administrado. Así se desata la delincuencia violenta.

Palabras clave: educación, pobreza, delincuencia, violencia, México. 


\section{Introducción}

México atraviesa por una enorme crisis de violencia social; probablemente la más grande de su historia. La alarma se ha expandido por todas partes y ha incitado el ensayo de varias explicaciones. La más socorrida es la que señala a la pobreza y a la falta de oportunidades educativas como los orígenes de índole estructural, que deben ser atendidas por las políticas públicas. Una sociedad más pobre y más educada, se piensa, acarreará una incidencia delictiva más baja, incluida la que involucra dosis notorias de violencia. Algunos casos nacionales avalarían esta posición: Suiza, Japón, Canadá y los países escandinavos (Meghir et al., 2012), en un polo; y los países del África subsahariana, en el otro (Hjalmarsson y Lochner, 2012).

Tras esta idea se despliega una secuencia de supuestos sobre el comportamiento humano que la modernidad ha impulsado, mientras que la pre y la posmodernidad se han encargado de debilitar. El primero de ellos es que los individuos persiguen su propio interés, pero la sociedad restringe esta búsqueda hasta constreñirla solo a la esfera de la legalidad. De esta forma, ese interés se ve socialmente modificado, en la medida que el resultado neto del beneficio - determinado por el riesgo de ser sancionado y el tamaño del castigo-deriva en un incentivo lo suficientemente poderoso para inhibir las conductas delictivas.

Esto es lo que se encierra detrás de la visión hobbesiana de la modernidad (Hobbes, 1982). El segundo es que la educación contribuye de manera decisiva a detener esos impulsos o, como quería Rousseau (2000), a reconvertirlos para dar cauce al hombre bueno y natural. De cualquier modo, la idea es que la educación es portadora de una enseñanza invaluable: el arreglo social de acuerdo con la Virtud, que hace posible la emergencia de ciudadanos libres y solidarios. Conforme a este pensador, el progreso representaría la forma para abandonar la pobreza; así se pierde un incentivo para delinquir. Pero no es suficiente: el afán de riquezas, involucrado en la búsqueda del interés propio, debe ser refrenado por un Estado que destierre la impunidad, así como por una educación que convence de que la armonía social es la mejor forma en la cual los individuos pueden convivir en comunidad.

En este sentido, la relación que nos vincula a una mayor educación con un menor grado de delincuencia ha encontrado el aval de otros investigadores. Por ejemplo, Nateras y Zaragoza (2017) señalan que en México la deserción escolar es uno de los factores sociodemográficos determinantes de la delincuencia. De manera similar, en Uruguay, los adolescentes detenidos suelen ser hombres con un bajo nivel educativo, que tuvieron problemas para 
su inclusión en las instituciones educativas y en el ámbito laboral (Trajtenberg y Eisner, 2015). Por su parte, Huang (2016) apunta que la relación entre delincuencia y educación se cruza en la deserción durante el bachillerato.

Sin embargo, el lazo de la delincuencia con la pobreza es menos contundente. Los casos nacionales mencionados antes admiten otros contraejemplos: es el caso de Italia, donde al lado de un aceptable nivel de bienestar convive una actividad mafiosa, no solamente en el sur más tradicional, sino también en otras partes del país. En el mismo México se encuentra que la violencia prolifera ahí donde la comunidad es más próspera; mientras tanto, en entidades como Oaxaca y Chiapas no se manifiesta, ni lejanamente, en similares proporciones, a pesar de ser catalogados como estados con mayores grados de pobreza.

Por tal razón, la debilidad de este vínculo es más acentuada que en el caso de la educación. Así lo han indicado autores como Guillén (2006), Ortega (2010), Nateras y Zaragoza (2017), Trajtenberg y Eisner (2015). Todos ellos han declarado que la pobreza no es un factor decisivo para explicar la delincuencia: existen otros factores que activan la predisposición individual a delinquir, y la pobreza es solo uno de ellos.

El objetivo de este trabajo de investigación es revisar las relaciones entre educación, pobreza y delincuencia, precisamente porque: a) el vínculo de esta última con la pobreza es ambigua y, en todo caso, debe distinguirse entre las transgresiones asociadas con la violencia y aquellas que no la involucran; y b) la educación no necesariamente actúa en el sentido esperado por el paradigma de la modernidad, en el sentido de que aquella reduce la pobreza y abate el crimen. De hecho, a través de diez modelos de regresión lineal se obtienen distintos resultados: la pobreza y la educación no inciden directamente en la violencia delictiva, pero sí actúan sobre ella de forma indirecta: mediante los delitos contra la salud. ${ }^{1}$

En segundo término, la delincuencia del fuero común y exenta de la violencia es afectada directamente por la pobreza y el nivel educativo, pero en el sentido inverso al que por lo general se le confiere: una sociedad más educada, apuntan Tierney (2015) y Hannum et al. (2017), aliviará la pobreza y sus consecuencias, entre las que podemos relacionar la incidencia delictiva, incluso la que involucra dosis notorias de violencia. Los resultados de la presente investigación indican lo contrario.

La consecuencia de estos resultados para la política pública en materia de educación y el combate a la pobreza es valiosa por sí misma, en la medida que enriquece el desarrollo de las capacidades de los individuos (Sen, 2000). Su

1 En México, el narcotráfico se cataloga como "delitos contra la salud". 
promoción no promete logros de corto plazo, en términos de reducción de la violencia, aunque sí en términos del delito del fuero común. Esto significa que mientras este último es una expresión de las condiciones sociodemográficas, la violencia obedece a factores diferentes, más cercanos a la configuración de una actividad empresarial, en la que el nivel educativo aporta, aunque no necesariamente, un insumo rentable.

Estos resultados guían la exposición de las líneas siguientes. En el primer apartado se presenta la metodología, que consiste en diez modelos, divididos según el carácter violento o no violento de la delincuencia. El propósito es encontrar los elementos distintivos y similares que los caracterizan. En la siguiente sección se presentan los resultados para analizar los vínculos entre educación, pobreza y delincuencia. Primero se aborda el papel que desempeñan en la proliferación de la violencia delictiva; después se hace lo mismo, pero en el caso de los delitos del fuero común que excluyen el homicidio doloso. En la tercera sección se ensaya una interpretación de los resultados, fincada en las características híbridas del sistema político mexicano y su derivación en un esquema de impunidad administrada, que se salió de control una vez que el poder político se descentralizó en épocas recientes. El último apartado incluye las conclusiones.

\section{La metodología y sus resultados}

Aunque la violencia delictiva se puede manifestar en varias dimensiones, los homicidios dolosos suelen presentarse como una buena proxy ${ }^{2}$ de la agresividad. La razón estriba en que la exhiben en sus grados más extremos. También representan una ventaja para los investigadores: es más frecuente su denuncia y más preciso su registro. Otros delitos, como el robo con violencia o las agresiones, no siempre se denuncian (Zepeda, 2004); y, en este rubro, las cifras del Secretariado Ejecutivo del Sistema Nacional de Seguridad Pública (SESNSP, 2018) y la Encuesta Nacional de Victimización y Percepción sobre la Seguridad Pública (ENVIPE) suelen divergir de manera más notoria (INEGI, 2017a).

En este sentido, la variable seleccionada para dar cuenta de la violencia delictiva es la tasa de homicidios por cada 100,000 habitantes. Las cifras las suministra directamente el SESNSP (2018). Lo mismo sucede con los otros dos indicadores que se utilizan en esta exploración: los delitos contra la salud y los de fuero común (netos del número de homicidios).

2 Es una variable que aproxima a otra variable, cuando esta última no puede ser medida directamente. 
Estos datos permiten distinguir la actividad delictiva en: violenta y aquella en la que aunque la violencia puede estar involucrada no representa la esencia misma de la actividad, ni mucho menos se despliega hasta aniquilar la vida de la víctima. La división es importante para los propósitos de este trabajo, porque se tratará de probar lo que se piensa intuitivamente: que ambos grupos de transgresiones responden a lógicas distintas, y que solo de forma muy indirecta pueden vincularse con la educación y la pobreza.

Para estudiarlos, se propone una metodología de diez modelos que admiten una clasificación general, donde dos son las variables dependientes: la tasa de homicidios dolosos y la tasa de delitos del fuero común, con exclusión de estos últimos. La búsqueda de los determinantes de ambas variables se despliega de manera deductiva, a medida que la estimación pone a prueba, desecha y retiene factores incidentes. Cuando estos son ubicados como determinantes significativos, pasan a ocupar el lugar de la variable dependiente en el siguiente modelo, hasta que el ajuste (aproximado por el coeficiente de determinación) avisa que ya no puede mejorarse con la inclusión de variables asociadas a la pobreza-desigualdad y/o la educación.

Las primeras están conformadas por las incidencias de la pobreza y de la pobreza extrema, así como por el Î́ndice de Gini. Las segundas, por la proporción de personas con rezago educativo, el promedio de escolaridad, la tasa de abandono de la educación media y el premio educativo. Todas las variables, dependientes y explicativas, se nutren de las cifras que registran cada una de las entidades federativas. Las fuentes son las siguientes: las cifras de pobreza, desigualdad y rezago educativo provienen de Coneval (2017); y la tasa de abandono en educación media y el promedio de escolaridad, del SNIEE (2017).

El premio educativo merece una explicación aparte. Se refiere al ingreso promedio estatal que aporta (o resta) un año de escolaridad en relación con su referente nacional. Se trata, entonces, de la diferencia entre producto per cápita (potencial) que debería registrar una entidad federativa si solamente reflejara su nivel de escolaridad (en relación con la nacional) y el PIB per cápita que efectivamente tiene. ${ }^{3}$ De manera formal se calcula así:

3 Las cifras del PIB per cápita fueron obtenidas de INEGI (2017b) y de Conapo (2017). 


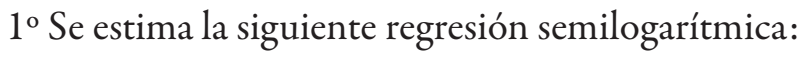

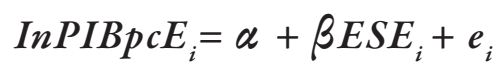

Donde InPIBpcE $E_{i}$ es el logaritmo del PIB per cápita de la entidad federativa i-ésima; y $\boldsymbol{E} \boldsymbol{S} \boldsymbol{E}_{i}$, su nivel medio de escolaridad; $\mathrm{e}_{\mathrm{i}}$, el residuo de la regresión. $\alpha$ es la constante de la regresión; y $\beta$, el regresor, que refleja la variación o diferencia porcentual que se deriva de un año de escolaridad, respecto al promedio nacional.

$$
\frac{d P I B p n E}{\text { PIBpnE }}=\beta d E S E
$$

El resultado de la estimación es el que se presenta en el Cuadro $1 .{ }^{4}$

$2^{\circ}$ Cálculo del PIPpcE potencial, que correspondería únicamente al nivel de escolaridad. Este cálculo se estima como una diferencia porcentual respecto al nivel a los referentes nacionales:

$$
P I B p c P_{i}=P I B p c N\left[1+\left(E S E_{I}-E S N\right) 0.424\right]
$$

Donde $\boldsymbol{P I B P c P}_{i}$ es el producto potencial de la entidad i-ésima; $P I B p c N$, el PIB per cápita nacional; y $E S N$, la escolaridad promedio de México.

$3^{\circ}$ Estimación del premio (o castigo) de escolaridad, en términos porcentuales:

$$
\begin{aligned}
& P E S_{i}=\frac{P I B P c E_{i}}{P I B p c P_{i}}-1 \\
& \text { O, alternativamente: } \\
& 1+P E S_{i}=\frac{P I B p c E_{i}}{\text { PIBpcP }_{i}}
\end{aligned}
$$

4 Los cuadros y las gráficas se encuentran en el Anexo, al final del presente artículo (Nota del editor). 
De esta forma, si:

- $P E S_{i}>0$ o, alternativamente, $\frac{P I B P c E_{i}}{P^{2} P p c P_{i}}>1$, la entidad registra un ingreso per cápita mayor que el que debería tener, si se atendiera exclusivamente a su grado de escolaridad.

- $P E S_{i}=0$ o, alternativamente, $\frac{P I B p c E_{i}}{P_{B} P c P_{i}}=1$, la entidad registra un ingreso per cápita igual que le correspondería por su escolaridad promedio.

- $P E S_{i}<0$ o, alternativamente, $\frac{P I B P c E_{i}}{P I B p c P_{i}}<1$, la entidad ostenta un ingreso per cápita inferior al que debería tener, si tomáramos en cuenta solo la escolaridad.

La razón de incorporar el premio educativo obedece a una interpretación muy socorrida, según la cual los rendimientos de la educación inciden en la delincuencia, en la medida en que esta representa una actividad económica más rentable. El motivo de este argumento lo encontramos en el carácter privilegiadamente instrumental que el discurso de la modernidad otorga a la educación: esta debe servir para integrarse en los mercados laborales y a partir de ahí obtener un emolumento.

Esta es la lógica que se halla detrás de los primeros trabajos de capital humano (Becker, 1980): las personas invierten en educación con la esperanza de obtener un ingreso que compense los gastos involucrados y, además, suministre un excedente que permita superar el nivel de vida que se tendría en ausencia de esa inversión. Cuando la educación no brinda ese rendimiento, los agentes racionales buscarán actividades alternativas; entre ellas, la delincuencia, si la utilidad esperada (beneficio ponderado por el riesgo de ser castigado) es mayor. En virtud del alto grado de impunidad que prevalece en México y de la expansión de la oferta educativa, que se ha traducido en una declinación relativa del bono educativo (Millán, 2013), cabría esperar que el premio fuera un determinante importante. Esto se analizará más adelante. 
Por lo pronto, se expone la estructura analítica de los diez modelos, a través de esta formulación general:

$$
\begin{aligned}
& Y_{i j}=\gamma+\beta_{k} \sum_{k=1}^{n} X_{j k}+u_{i j} \\
& X_{j k}^{*}=\delta+\rho_{q} \sum_{q=1}^{m} Z_{j k q}+\varepsilon_{j k}
\end{aligned}
$$

Donde $Y_{i j}$ es el delito o el fenómeno social j-ésimo, de la entidad federativa i-ésima, que es explicado por la determinante $X_{.}$; y $\boldsymbol{u}_{i j}$, es el término de error de la regresión lineal. $X^{*}{ }_{j k}$ son las variables independientes que resultaron estadísticamente significativas; $\boldsymbol{Z}_{j k q}$, sus determinantes.

La generación de los modelos opera de forma secuencial. Inicia con la inquisición de los determinantes de los delitos violentos, por un lado, y los del fuero común sin homicidios, por el otro; de ahí prosigue con los determinantes de los determinantes. El proceso se detiene cuando el coeficiente de determinación baja o no se altera.

\section{Resultados}

Por cuestión de orden, el análisis de los resultados se ha dividido en dos secciones: en la primera se examina la influencia sobre la violencia que registran la educación y la pobreza; en la segunda, se les inspecciona en relación con la delincuencia no violenta: la que no se asocia al homicidio intencional. Los resultados de la estimación se presentan en el Cuadro 2.

\section{La violencia delictiva: educación, pobreza y tasa de homicidios dolosos}

La violencia se manifiesta de muchas maneras. Sin embargo, la guerra del Estado mexicano contra los cárteles de la droga, iniciada en 2006, no solo la ha relanzado hasta alcanzar niveles sin precedentes, sino también ha hecho que cada vez se le identifique con su forma más extrema: el homicidio doloso. Por tal razón, se ha escogido la tasa de homicidios por cada 100,000 habitantes como proxy de este fenómeno social.

Precisamente porque su evolución está asociada con aquella guerra, la intuición condujo a un primer modelo, que hace depender a ese indicador 
de la tasa de delitos contra la salud. Como se puede apreciar en el Modelo 1, esta variable es estadísticamente significativa y exhibe una relación positiva con los homicidios dolosos por cada 100,000 habitantes: esta tasa aumenta (o disminuye) cuando lo hace aquella razón delictiva.

Sin embargo, el coeficiente de determinación $\left(\mathrm{R}^{2}\right)$ advierte que esta última es responsable de $31.6 \%$ de las diferencias que, en este rubro, exhiben las entidades de la República. Por tal razón, se adicionan las variables socioeconómicas en el segundo modelo, y las educativas en el tercero. En ambos, la tasa de delitos continúa siendo significativa, pero eleva un poco su capacidad de explicación (de 2.255 a 2.512 y 2.449 , respectivamente). Lo sorprendente es que ninguno de los dos conjuntos de variables explicativas - pobreza moderada, extrema y desigualdad, por un lado; y abandono escolar, promedio de escolaridad, premio y rezago educativo, por el otroresultaron significativas. Es más, el coeficiente de determinación, que debería subir con la incorporación de más argumentos, permanece inalterado o baja un poco.

Esto quiere decir que se debe buscar el resto de factores explicativos de la violencia en otra parte, no en la pobreza y la desigualdad o en las oportunidades educativas, como podría proponer un discurso de facilismo sociológico.

Pero el verdadero sentido de esta indeterminación se ubica en los resultados de los modelos 4 y 5 . En ellos se inquiere por los factores causales de la tasa de delitos contra la salud, lo cual a su vez explica las discrepancias que, en el rubro de los homicidios, registran los 32 estados. En ambos, es la incidencia de la pobreza moderada la que afecta esta nueva variable dependiente, y lo hace con alrededor del 30\% de explicación. La pobreza extrema, la desigualdad y los fenómenos educativos no contribuyen en nada a esta tarea. Lo que estos resultados dicen es que la pobreza influye, pero solo indirectamente en la violencia nacional. Y, en segundo término, que la causalidad se da en el sentido contrario al que usualmente se le da a esta relación: una disminución (aumento) de la pobreza moderada aumenta (baja) la tasa de delitos contra la salud y, por esta vía, incrementa (abate) la violencia delictiva.

Por ello resulta congruente con el panorama que muestra la geografía mexicana: en los estados con sociedades más ricas, como es el caso del norte y el Pacífico central, proliferan más el narco y los asesinatos intencionales, que en sus contrapartes del sur-sureste, donde la pobreza es mayor, y la tasa de delitos contra la salud, menor. Esta relación se exhibe en las gráficas 1, 2 y 3.

Una primera conclusión es que la pobreza influye en la violencia siempre y cuando exista la presencia de alguna modalidad de narcotráfico en la sociedad. De lo contrario, la influencia es nula. La razón estriba en que las 
actividades asociadas a la droga proliferan en sociedades no pobres; o mejor, ahí donde hay dinero y este se difunde de forma relativamente razonable, hasta evitar que la pobreza sea un fenómeno generalizado. El Cuadro 3 muestra esta correlación.

Como se puede observar, hasta ahora no se aprecia ninguna ascendencia de los factores educativos sobre la delincuencia violenta. Ni siquiera sobre su principal determinante: el narcotráfico. Sin embargo, el Modelo 6 abre la puerta para tal influencia. Muestra que la incidencia de la pobreza, que afecta negativamente la violencia a través de los delitos contra la salud, está determinada solo por un factor educativo: el promedio escolar. Ni la desigualdad ni otros componentes educativos, como el abandono o el premio escolar, afectan la proporción de pobres en la población. Tampoco lo hace la desigualdad, estimada por el Gini. Es más: el promedio de escolaridad exhibe un nivel muy alto de explicación de la incidencia de la pobreza: alrededor del 75\%, como lo muestra el coeficiente de determinación ajustado.

Este último hallazgo permite dibujar la cadena de causalidad: el promedio escolar mayor (menor) reduce (aumenta) la incidencia estatal de la pobreza; y esta influencia estimula (inhibe) la proliferación de los delitos contra la salud. Al hacerlo, subirán (bajarán) los homicidios dolosos por cada 100,000 habitantes, que se ha escogido como proxy de la delincuencia delictiva. Por tanto, los factores educativos y la pobreza inciden en la violencia de forma indirecta: siempre y cuando se reflejen en una variación de la tasa de delitos contra la salud; pero lo hacen en el sentido contrario al generalmente señalado.

La inclusión del premio educativo tiene una finalidad: examinar la hipótesis de que las actividades delictivas, en especial las violentas, compiten con el premio educativo. Millán (2013) ha demostrado que el que ofrecen los grados medios y superiores de enseñanza se ha reducido, en relación con los de la educación básica. Se trata de una evolución en el tiempo, y se vincula con la creciente oferta de mano de obra con nivel secundario, frente al escaso dinamismo de la demanda de obra calificada, acicateado por el lento ritmo de crecimiento económico de los sectores que apuntalan la acumulación de capital en México.

Así, cabría esperar que en los estados de la República con mayor premio educativo la tasa de delincuencia fuera menor. Sin embargo, tanto el nivel de significancia como los coeficientes de correlación muestran que no ha sido el caso, cuando el examen se realiza de forma transversal, con el propósito de 
resaltar las diferencias entre entidades federativas. ${ }^{5}$ Con ello se desmonta la creencia generalizada de que la educación compite con las actividades delictivas, en términos de su rendimiento.

\section{Los delitos del fuero común (sin homicidios dolosos)}

Los homicidios dolosos forman parte de los delitos del fuero común, pero se ha decidido excluirlos de estos últimos, para enfocarse en actos no violentos o de una violencia atenuada, en el sentido de que no desembocan en la privación intencional de la vida. El objetivo - para decirlo en términos más claroses separar la violencia con más probabilidades de estar ligada al narcotráfico, de otro tipo de transgresiones que pueden o no incluirla, pero que no tienen la intención de interrumpir la vida de las víctimas y que, sobre todo, exhiben una lógica ajena a la economía de las drogas.

El Modelo 7 somete a prueba la determinación de las variables socioeconómicas (pobreza y desigualdad) y las educativas (abandono de educación media y promedio de escolaridad), mediante el mismo modelo de regresión. Los resultados arrojan que ninguna de estas variables explica la tasa de delitos del fuero común, exenta de los homicidios. Esto es así cuando ambos grupos son operados de forma conjunta; pero cuando se toman de forma aislada la incidencia de la pobreza (Modelo 8) o el promedio de escolaridad (Modelo 9), ambas variables son estadísticamente significativas y explican entre 25.8 y $23 \%$ de las discrepancias estatales de la tasa delictiva. Por su parte, el modelo 10 advierte que, juntas, la pobreza y la educación nopueden explicar esta última.

\section{Sistema político e impunidad: el modelo híbrido rentista y la dispersión del poder}

Para encontrar el sentido de estos datos, conviene desmenuzar los resultados. En primer lugar, tanto la incidencia de la pobreza como el promedio de escolaridad anulan su influencia en presencia de las otras variables socioeconómicas y educativas, lo cual revela la incapacidad de ambas para incidir en la tasa delictiva. Tal hecho destierra dos explicaciones socorridas: que la delincuencia puede estar provocada por la desigualdad, en la medida en que una mayor concentración del ingreso genera un sentido de "envidia" o de frustración

5 El coeficiente de correlación de Pearson entre el premio educativo, por un lado, y la tasa de delitos del fuero común, la de delitos contra la salud y la de homicidios, por el otro, resultaron estadísticamente no significativos. 
sociales, que impulsan a los individuos a la violencia y/o a la delincuencia, que, a su vez, permite la nivelación por vías ilegales. Ni en el caso de los homicidios dolosos ni en los del fuero común que los excluyen esta proposición es cierta.

Al parecer, la desigualdad social no desencadena movimientos de ilegalidad colectiva o individual, por más injusta que parezca. Su presencia anula el efecto determinante de la pobreza y de la educación, lo cual significa que, en una sociedad pobre, o menos pobre, pero más educada, se tiende a aceptar la desigualdad o a disociarla de un sentido de injusticia.

Las razones pueden ser varias. El teorema del votante mediano (Downs, 1957) predice que la democracia impulsará políticas distributivas (Milanovic, 2000). Análogamente, se podría argumentar que cuando no sucede así, ya sea porque no existen mecanismos democráticos de gestión pública o porque estos no conducen a estas predicciones (Benhabib y Przeworski, 2006), se activan mecanismos ilegales que llevan a una cierta redistribución deliberada. Sin embargo, no parece ser el caso.

Shapiro (2003) argumenta que existen tres elementos que impiden tal distribución: separación física entre ricos y pobres; golfos de empatía, que conducen a los menos afortunados a admirar y a tratar de emular a los más ricos; y la marginalización de los pobres, operada por las clases medias y altas. Los tres componentes operan en México para impedir que la desigualdad genere un sentido de injusticia que, eventualmente, acarrearía más delincuencia como estrategia redistributiva.

La causa estriba en que la desigualdad atraviesa tanto a sociedades ricas y modernas como a pobres y premodernas. ${ }^{6}$ Empero, en las dos tal disparidad es procesada de forma distinta. En comunidades premodernas, regidas por vínculos personales y mecanismos extrainteresados de cohesión social, el proceso de individuación es prácticamente nulo. En este sentido, todo tipo de diferenciación social, incluida la delincuencia individual, es inhibida por los mecanismos informales de control y autocontrol que ejerce la comunidad (Boix, 2015): desde la burla y el desprecio social, hasta los castigos fuera de la ley (el linchamiento es un caso extremo).

En estos núcleos poblacionales, la delincuencia - cuando se da- reviste un rasgo comunal, que se asocia con un sentido de injusticia y de participación colectiva, que imprimen un alto grado de legitimidad a la delincuencia. Y la desigualdad no les confiere tal sentido de injusticia: se trata de comunidades insertas en conglomerados más amplios, signados por un estatus jerárquico, que proviene de cierto orden natural, en la medida en que tal estratificación es necesaria para la supervivencia.

6 El coeficiente de correlación de Pearson entre el Índice de Gini y el PIB per cápita estatal fue de 0.069 y no significativo: sig.: 0.709 . 
Por otro lado, en sociedades modernas, los procesos de individuación son intensos y, en buena medida, definitorios de tales sociedades. El incentivo para diferenciarse por medio de delitos orientados a ensanchar el patrimonio es grande. No obstante, también se rigen por criterios meritocráticos, que imprimen a la desigualdad un carácter exento de injusticia. Antes de provocar la "envidia social", activa mecanismos de simpatía hacia quienes más tienen, que suelen ser alimentados por la difusión televisiva de las formas de vida de los que poseen más.

Ahí se exhiben biografías que unen en lo profundo - las pasiones, los sentimientos y problemas - a todos, a pesar de la distancia física y la marginación que separa a ricos y pobres. Es el mismo proceso de "empatía" que provocaron las novelas del siglo XIX para extender el reconocimiento de los derechos humanos a todas las razas y estratos de población (Hunt, 2008). Estos mecanismos suelen desterrar la desigualdad de los causales del delito del fuero común.

En segundo término, debemos reparar en el sentido de la causalidad de los determinantes. Al igual que en el caso de la tasa de homicidios dolosos, una disminución (alza) de la pobreza o un aumento (abatimiento) del promedio de escolaridad empuja al alza (a la baja) los delitos del fuero común, exentos de aquellas transgresiones. La explicación es similar: la prosperidad es condición para que el delito se vuelva atractivo. Sin embargo, no es suficiente; es preciso un ingrediente adicional: la impunidad. En las sociedades tradicionales, suele imperar la penuria y la escasez de recursos, al tiempo que existen mecanismos informales de castigar la transgresión. Pero también el recelo de preservar las costumbres y las normas que rigen la convivencia social, así como el carácter cuasi familiar de esas comunidades, hacen muy improbable la impunidad: hasta el personaje más cercano deviene un vigilante y delator potencial del transgresor.

De esta forma, es difícil que alguien salga impune. En esas comunidades premodernas la pobreza incide con mayor amplitud, y el nivel educativo suele ser menor. En este sentido, se explica fácilmente el signo de la causalidad: mayor pobreza y menor escolaridad conducen, combinadas con un menor grado de impunidad, a una menor tasa de delitos.

En el otro extremo, las sociedades modernas suelen ser más prósperas, pero también más apegadas a la ley. La primera cualidad activa un fuerte incentivo para delinquir; no obstante, este es frenado por una aplicación más eficaz de las prescripciones legales. Los países de Norteamérica y de Europa occidental son un ejemplo de ello: ahí la menor pobreza y la escolaridad más alta y difundida tienden a abatir la tasa de delitos. 
Sin embargo, cabe preguntarse por los ejemplos híbridos, como en el caso de México. La comunidad premoderna y la moderna coexisten casi desde su nacimiento. Los intentos de una y de otra por el predominio desembocaron, prácticamente desde finales del siglo XVIII y hasta el último tercio del XIX, en conflictos constantes, que a menudo se tradujeron en confrontaciones bélicas. Así se puede entender que los intentos de modernización de las reformas borbónicas, los liberales y el impulso de Salinas de Gortari, fueron sucedidos por las guerras de independencia, la Revolución de 1910 y la revuelta en Chiapas, respectivamente. Los hombres de la Reforma y del Porfiriato encontraron la solución, que prosiguieron los posrevolucionarios: el equilibrio entre los actores sociales, tejido por una distancia administrada entre la ley y su aplicación.

La presencia de las disposiciones jurídicas satisfacía las demandas de los modernos; la aplicación discrecional, la de los premodernos. De esta forma, surge una institucionalidad "blanda", que da lugar a un Ejecutivo fuerte y con capacidades arbitrales, quien al lado de sus facultades formales ostentó otras de carácter metaconstitucional. El dilema entre gobernabilidad y democracia se resolvió mediante el sacrificio de este régimen; pero también mediante la conformación de un Estado vigoroso, capaz de penetrar las dimensiones más remotas del espectro social y de tutelar a toda la sociedad.

Pero la consecuencia más importante para los presentes propósitos fue la aparición de un tipo degenerado de premodernidad: el rentismo. El equilibrio entre actores sociales, el manejo arbitral de sus potenciales conflictos y de los que emergían entre las élites políticas, demandaron concesiones a empresarios cuasi monopólicos y la configuración de un esquema corporativo que entregaba a los sindicatos y organizaciones sociales otro monopolio: el de la representación gremial. En ambos proliferaron mecanismos de gestión del bienestar elitista, independientes de la productividad, y orientados hacia la extracción de rentas.

El rentismo se finca en el privilegio que otorga la cercanía al poder y en la delegación de sus mecanismos. Va desde el líder sindical que ejerce una gran capacidad de veto sobre las políticas educativas o energéticas, hasta el burócrata que puede extraer una "mordida" del ciudadano que solicita un servicio determinado. Pero también desde el gran empresario que obtiene canonjías especiales de las altas autoridades, hasta el inspector que se hace de la "vista gorda" cuando inspecciona, por ejemplo, un centro de trabajo, a cambio de una coima. En todos estos casos hay desvíos de la ley a cambio de rentas que no están ligadas a la productividad o al esfuerzo laboral. La impunidad se instala, entonces, como una forma discrecional de mantener 
el equilibrio actoral. Pero se trata de una impunidad administrada, sujeta a las necesidades arbitrales que requiere ese equilibrio.

Sin embargo, para que alguien pueda extraer una renta, es necesario que otro agente produzca. Esto es lo que advertía Ricardo (1988) al marcar la asociación conflictiva entre empresarios agrícolas y terratenientes. La prosperidad es estimulada para que aquella sea posible, aunque al final represente un freno de largo plazo. Y esa prosperidad es impulsada por los actores modernos de la sociedad.

Así, el modelo premoderno rentista posibilita cierta prosperidad acotada por la extracción de rentas, pero también instala las bases para la gestión de la impunidad. Ambas son esenciales para el mantenimiento del equilibrio que posibilita la gobernabilidad. De este modo se cimientan las dos condiciones para que la incidencia de la pobreza se relacione negativamente con la tasa de delitos del fuero común.

Lo novedoso es que la misma correlación se da con la tasa de delitos violentos: los homicidios dolosos. Para que esta opere y la violencia se desboque es necesario que la impunidad pierda su carácter administrado, porque así se reduce el costo de incurrir en esas transgresiones y el riesgo de ser castigado. La pérdida fue detonada por el debilitamiento del Estado y el menoscabo, hasta la desaparición, de las capacidades arbitrales del Ejecutivo. Anteriormente, tanto la maquinaria estatal como el papel central que el Presidente, sus delegados (ministros, gobernadores y presidentes municipales) y el partido oficial jugaban en lo que Michael Mann (citado por Loaeza, 2010) llamó el poder infraestructural y el poder despótico, posibilitó que la estabilidad y la paz sociales estuvieran bajo control. Estos consistían en la penetración de la hegemonía en todos los rincones geográficos y en todas las relaciones de base social, así como en el sometimiento de las élites a la cúspide política, respectivamente.

Con el arribo de la democracia, el poder se dispersó entre el Congreso, los partidos políticos y los gobernadores, así como entre los poderes fácticos, en desmedro de Ejecutivo. Este perdió su capacidad arbitral. Las políticas neoliberales, por su parte, desmantelaron el poder infraestructural al recortar los programas sociales o al sujetarlos privilegiadamente a criterios técnicos y presupuestales (Loaeza, 2010). De esta forma, el Estado perdió el control sobre grandes segmentos sociales y notables espacios geográficos. Así se perdió el carácter administrado de la impunidad. Los vacíos que dejó fueron llenados por poderes fácticos dedicados a actividades ilegales y violentas, que condujeron a una impunidad generalizada. El rentismo reclutó un nuevo actor social, ahora sin control del Estado: la delincuencia organizada, en especial la 
asociada al narcotráfico. Por tal razón, la pobreza afecta la tasa de homicidios dolosos solo a través de los delitos contra la salud.

El último aspecto que debe ser examinado es el papel de la escolaridad media. Esta se relaciona positivamente con el resto de los delitos del fuero común; pero a diferencia del caso de los homicidios dolosos, la influencia es directa. Una sociedad más educada es más propensa a la delincuencia común. Sin embargo, la conjunción con la pobreza conduce a la desaparición de su capacidad explicativa de ambas variables. El mensaje podría ser que la presencia de una de ellas es condición necesaria y suficiente para activar las variaciones interestatales de la delincuencia común.

Sin embargo, los datos confirman que ambas variables coexisten de manera indisoluble. Por tanto, el Modelo 10 debe ser juzgado como un esquema espurio. Y lo es: la ecuación de regresión que lo genera acusa una fuerte colinealidad entre la dimensión educativa y la pobreza. De hecho, como lo revela el Modelo 6, la incidencia de la pobreza puede ser expresada como una combinación lineal del promedio de escolaridad. Si se valida esta relación, entonces la lectura correcta es que esta media reduce (aumenta) la pobreza, y tal abatimiento (impulso) aumenta la tasa de delitos del fuero común, exentos de los homicidios dolosos.

\section{Conclusiones}

La pobreza, la educación y la delincuencia se encuentran asociadas; pero su influencia en la violencia es indirecta. Lo contrario sucede con los delitos del fuero común no violentos, en los cuales inciden de forma directa. Para que puedan traducirse en agresiones mortales, es preciso que las transgresiones que atentan contra la salud hayan arraigado en una sociedad determinada. Este arraigo, sin embargo, está asociado con los cambios que ha experimentado el sistema político mexicano. Cimentado en dos pilares - el corporativismo y el presidencialismo - fue diseñado con un propósito ulterior: gestionar la gobernabilidad, ante un panorama donde la heterogeneidad social representaba una continua y legítima amenaza tanto para ella como para la estabilidad social. La solución fue un equilibrio entre actores modernos y premodernos, tejido con la aplicación administrada de la ley.

Su mantenimiento demandó un Ejecutivo fuerte con capacidades arbitrales, así como un Estado capaz de imponer su dominación en todos los rincones y a todos los actores del espectro social. De esta forma, se instala la impunidad, pero esta es administrada gracias al control del Estado de casi todos los procesos sociales. Con el arribo de la democracia y las políticas neoliberales, 
el Estado pierde este control porque el poder se dispersa entre las élites y se desmantela la presencia estatal en la vida cotidiana. Así, la impunidad deja de ser administrada y se vuelve generalizada: se diluyen los frenos que impedían que la violencia se desbocara.

En el caso de los delitos menos violentos - los del fuero común, exentos de los homicidios intencionales-, la pobreza incide directamente en la tasa que los mide. Pero lo hace en el sentido contrario al cual estamos acostumbrados: una mayor prevalencia reduce la tasa; otra menor, la aumenta. La clave de esta relación es la existencia de un modelo rentista: un híbrido distorsionado de modernidad y premoderidad. El mismo carece de los mecanismos tradicionales que inhiben la transgresión, a través de la reprobación social y una alta eficacia punitiva, al tiempo que estimula y - secuencial y pendularmente- acota la producción.

Es el típico ciclo acumulación-redistribución. Sin embargo, en tal ciclo se impone una tendencia moderna hacia una mayor prosperidad, que es la base material del abultamiento de las rentas. De esta forma, arraigan el uso laxo de la ley, que conduce a la impunidad cotidiana, y una sociedad más rica. Ahí donde estos dos elementos coinciden, la pobreza se relaciona negativamente con la tasa de delitos del fuero común, sin contar los homicidios dolosos.

\section{Referencias}

Becker, Gary (1980), Human Capital: A theoretical and empirical analysis with special reference to education, Estados Unidos: The University of Chicago Press.

Benhabib, Jess y Przeworski, Adam (2006), "The political economy of redistribution under democracy", en Economic Theory, vol. 29, núm. 2, Estados Unidos: Springer.

Boix, Carles (2015), Political Order and Inequality, Estados Unidos: Cambridge Univesity Press.

Conapo (2017), Estimaciones y proyecciones de la población por entidad federativa. Disponible en: http://www.inegi.org.mx/sistemas/bie/?idserpadre=10200070\#D10200070 [1 de junio de 2018].

Coneval (2017), Medición de la pobreza: Anexo Estadístico 2016. Disponible en: https:// www.coneval.org.mx/Medicion/MP/Paginas/AE_pobreza_2016.aspx [1 de junio de 2018].

Downs, Anthony (1957), An economic theory of democracy, Estados Unidos: Harper Collins. Guillén, Francisco (2006), "Las políticas locales de prevención y seguridad en Europa”, en Revista Catalana de Seguretat Pública, núm. 16, España: Institut de Seguretat Pública de Catalunya.

Hannum, E. et al. (2017), "Evolving Approaches to the Study of Childhood Poverty and Education", en Comparative Education, vol. 53, núm. 1, Reino Unido: Taylor \& Francis Group. 
Hobbes, Thomas (1982), Leviatán. La materia, forma y poder de una república eclesiástica y civil, Colombia: Skla.

Hjalmarsson, Randi y Lochner, Lance (2012), “The impact of Education on Crime: International Evidence”, en CESifo DICE Report. Disponible en: https://economics. handels.gu.se/digitalAssets/1439/1439011_49-55_research_lochner.pdf $\quad[10$ de junio de 2018].

Huang, Bo-Ruey (2016), "Social Justice and Capacity for Self-development in Educational Systems in European Union”, en Education Provision to Every One: Comparing Perspectives from Around the World, BCES Conference Books, vol. 14, núm. 1, Bulgaria: Bulgarian Comparative Education Society.

Hunt, Lynn (2008), Inventing Human Rights: A History, Estados Unidos: Norton Company. INEGI (2017a), Encuesta Nacional de Victimización y Percepción sobre la Seguridad Pública. Disponible en: http://www.beta.inegi.org.mx/proyectos/enchogares/regulares/ envipe/2017/default.html [1 de junio de 2018].

INEGI (2017b), Producto Interno Bruto por entidad federativa. Disponible en: http://www. inegi.org.mx/sistemas/bie/?idserpadre $=10200070 \#$ D10200070 [ 1 de junio de 2018].

Loaeza, Soledad (2010), "La metamorfosis del Estado: del jacobinismo centralizador a la fragmentación democrática”, en Loaeza, Soledad y Prud'homme, Jean-Francois [coords.], Los grandes problemas nacionales. Instituciones y procesos politicos, México: El Colegio de México.

Meghir, Costas et al. (2012), "The Effect of Education Policy on Crime: An Intergenerational Perspective”, en NBER Working Paper, núm. 18145. Disponible en: https://ssrn.com/ abstract $=2085133$ [10 de junio de 2018].

Milanovic, B. (2000), “The Median-voter Hypothesis, Income Inequality, and Income Redistribution: an Empirical Test with the Required Data”, en European Journal of Political Economy, núm. 16, Países Bajos: Elsevier.

Millán, Henio (2013), En la cuerda floja. Vulnerabilidad hacia la pobreza y fragilidad laboral en México, México: El Colegio Mexiquense.

Nateras, Martha y Zaragoza, Daniel (2017), "La pobreza como indicador de generación de la violencia y la delincuencia en México", en Betancourt, Felipe [coord.], Reflexiones sobre el estado de derecho, la seguridad pública y el desarrollo de México y América Latina, México: Universidad Nacional Autónoma de México.

Ortega, José Antonio (2010), ¿Pobreza igual a delito? Los factores socioeconómicos del crimen y el derecho humano a la seguridad pública, México: Comisión de Derechos Humanos del Estado de México.

Ricardo, D. (1998), Principios de economía politica y tributación, México: Fondo de Cultura Económica.

Rousseau, Jean Jaques (2000), Emilio o de la educación, Argentina: elaleph.com.

Sen, Amartya (2000), Desarrollo y libertad, México: Planeta.

SESNSP (2018), Incidencia delictiva, abril, núm. 18. Disponible en: http:// secretariadoejecutivo.gob.mx/index.php [15 de junio de 2018].

Shapiro, Ian (2003), The State of Democratic Theory, Estados Unidos: Princeton University Press.

SNIEE (Sistema Nacional de Información y Estadística Educativa) (2017), Estadistica e Indicadores Educativos por Entidad Federativa. Disponible en: http://www.snie.sep. gob.mx/x_entidad_federativa.html [17 de mayo de 2018]. 
Tierney, William G. [ed.] (2015), Rethinking Education and Poverty, Estados Unidos: Johns Hopkins University Press.

Trajtenberg, Nico y Eisner, Manuel (2015), Towards a More Effective Violence Prevention Policy in Uruguay, Uruguay: University of Cambridge, Universidad de la República, Administración Nacional de Educación Pública.

Zepeda, Guillermo (2004), Crimen sin castigo, México: Centro de Investigación para el Desarrollo y Fondo de Cultura Económica.

\section{Anexo}

\section{Cuadro 1}

\section{Diferencia porcentual del PIB per cápita por año de escolaridad}

\begin{tabular}{lllll}
\hline & B & t & Sig. & R$^{2}$ Ajustada \\
\hline Constante & 7.849 & 10.198 & 0 & 0.448 \\
\hline Promedio de Escolaridad & 0.424 & 5.111 & 0 & \\
\hline Dependiente: LnPIBpcE & & & & \\
\hline
\end{tabular}

Fuente: Elaboración propia con datos de: INEGI, 2017b; SNIEE, 2017; Conapo, 2017. 


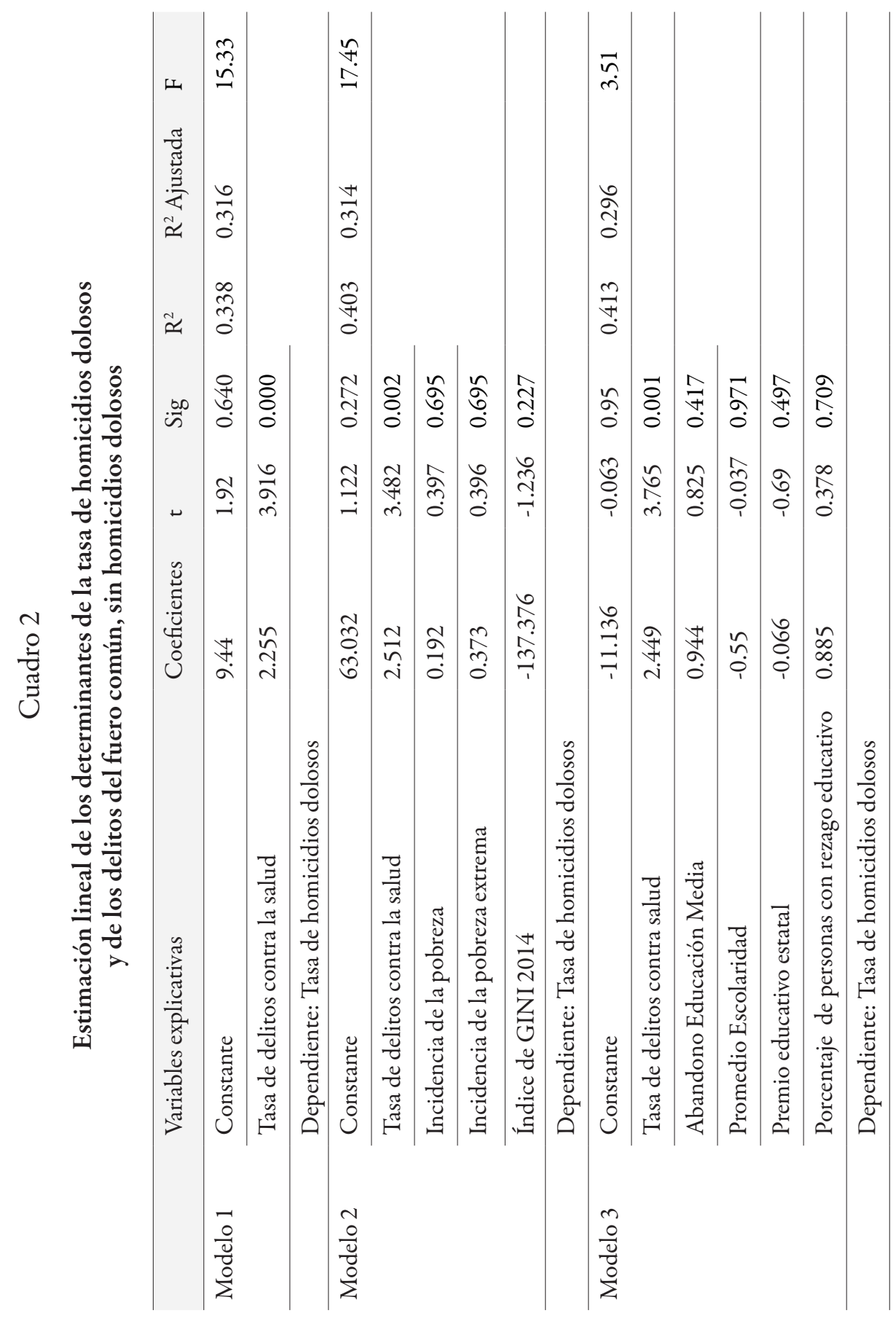


Henio Millán-Valenzuela y Eduardo Pérez-Archundia.

Educación, pobreza y delincuencia: ¿nexos de la violencia en México?

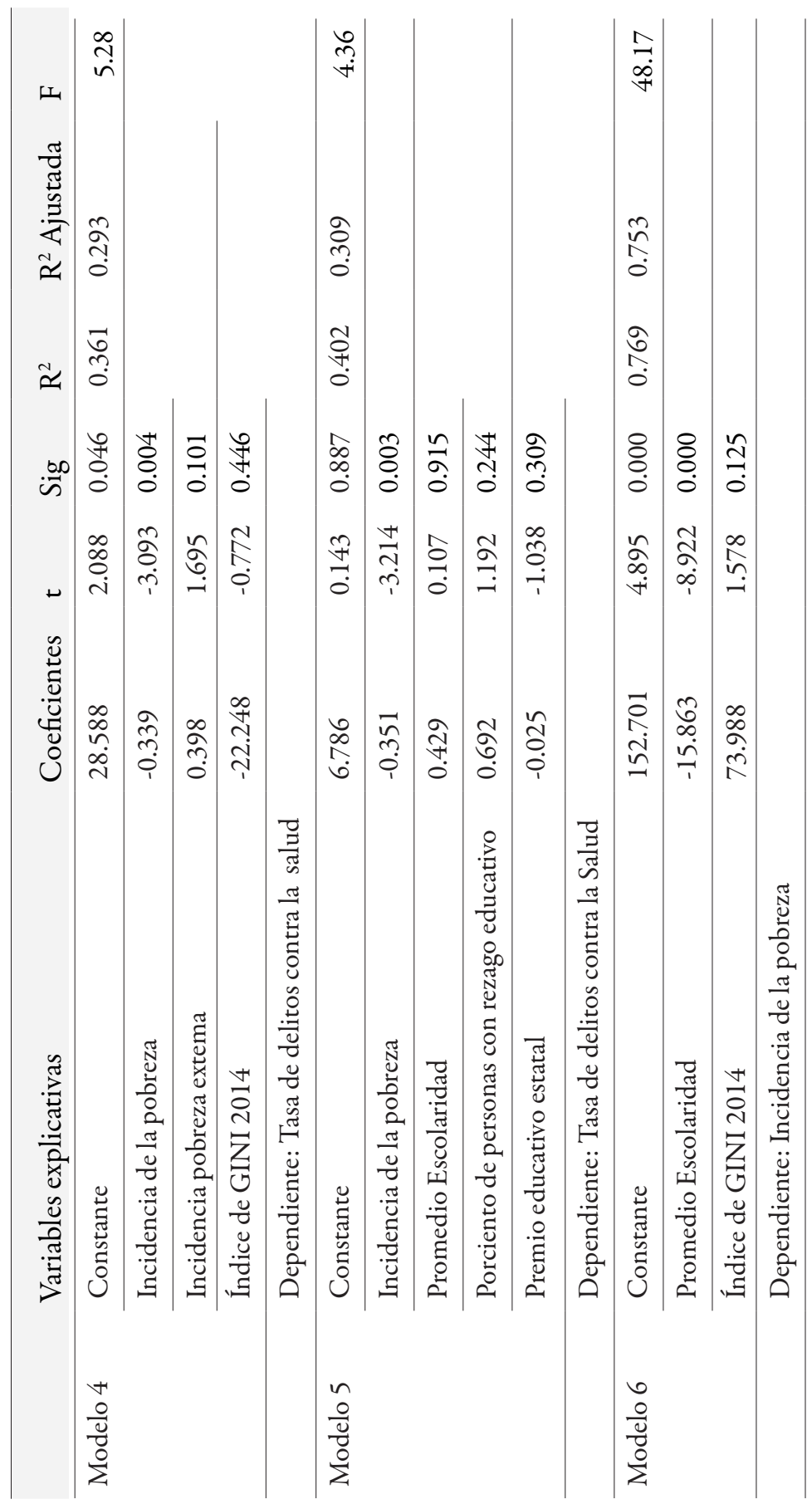




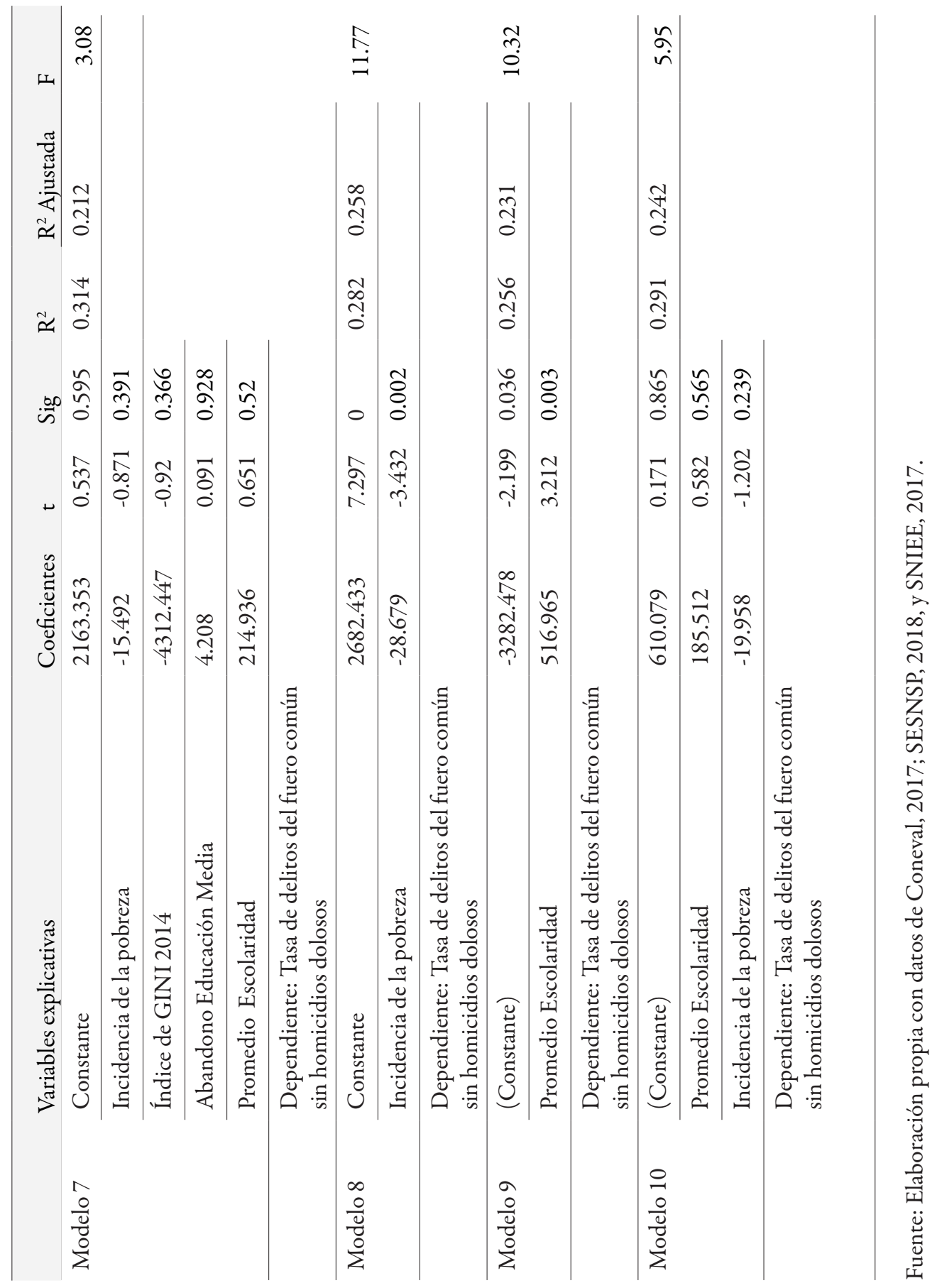


Henio Millán-Valenzuela y Eduardo Pérez-Archundia.

Educación, pobreza y delincuencia: ¿nexos de la violencia en México?

\section{Gráfica 1}

Tasa de homicidios dolosos por incidencia de la pobreza

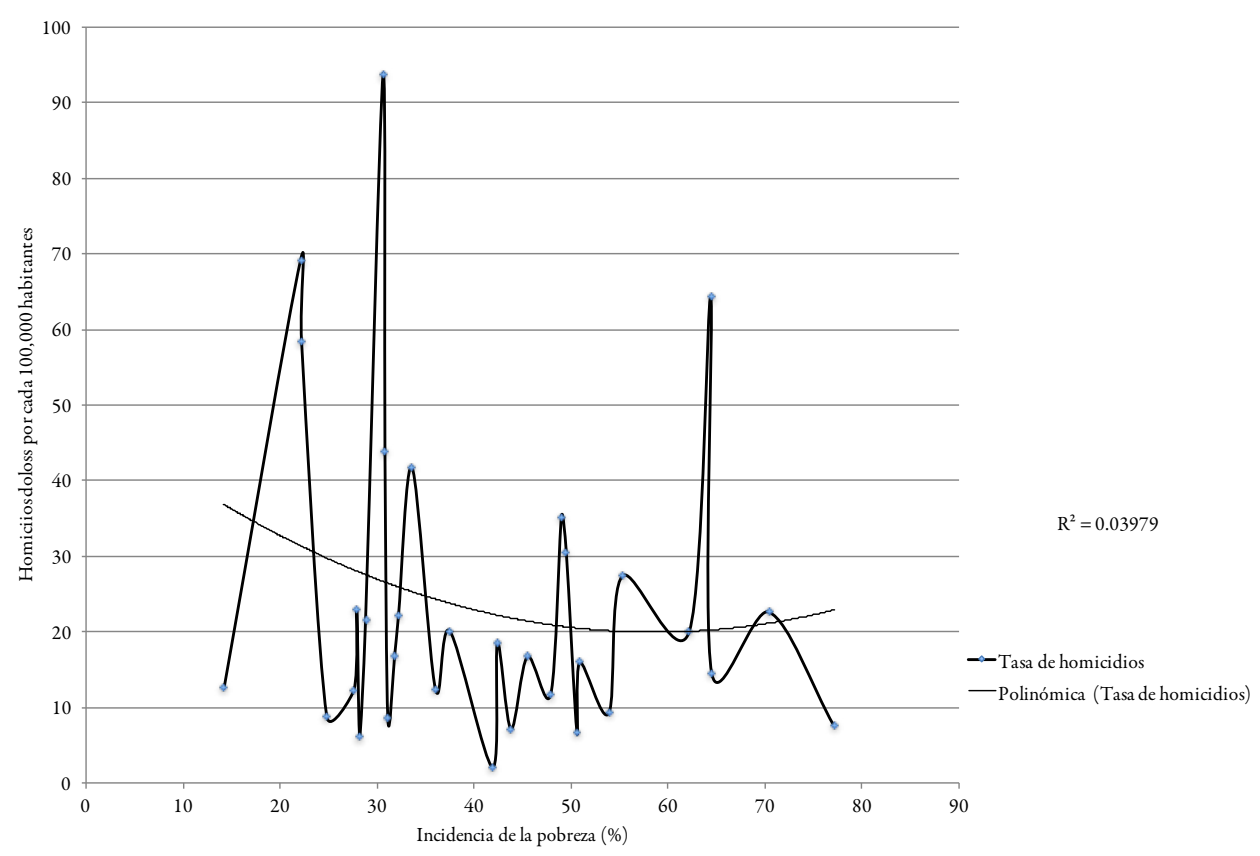

Fuente: Elaboración propia con datos de Coneval, 2017, y SESNSP, 2018. 


\section{Gráfica 2}

\section{Tasa de homicidios dolosos por tasa delitos contra la salud}

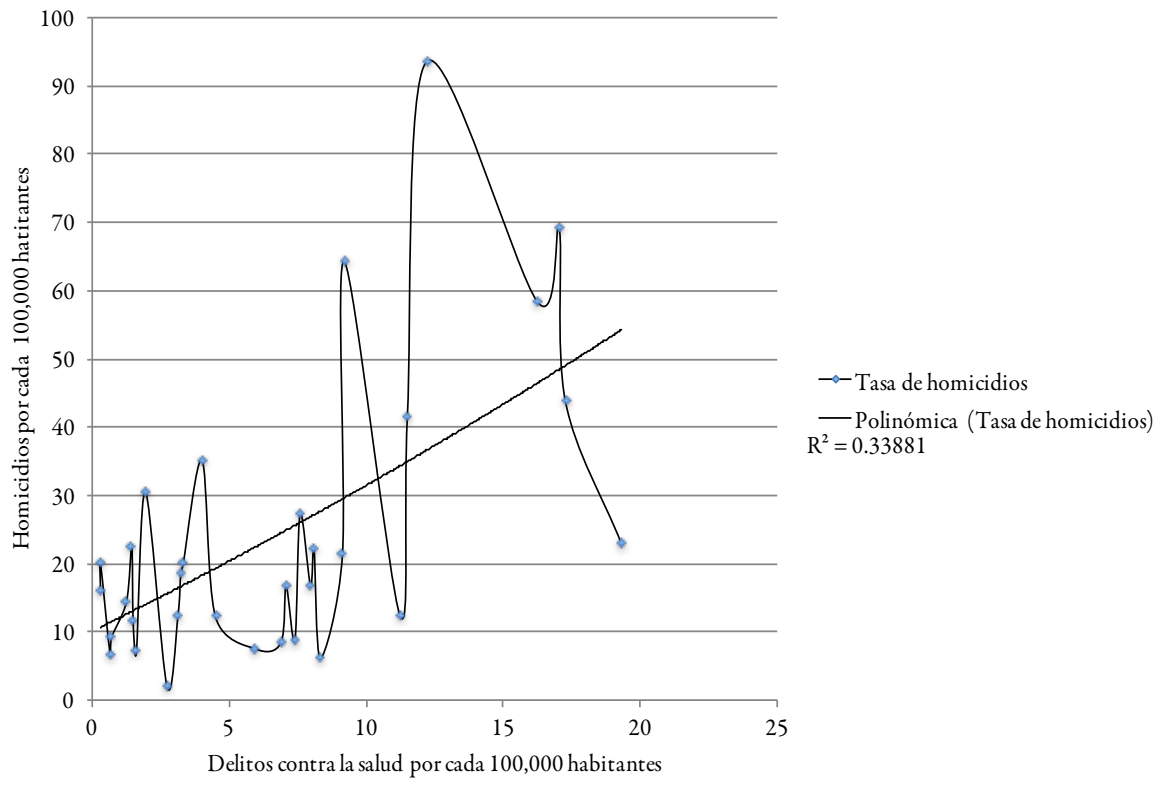

Fuente: Elaboración propia con datos del SESNSP, 2018. 
Henio Millán-Valenzuela y Eduardo Pérez-Archundia.

Educación, pobreza y delincuencia: ¿nexos de la violencia en México?

\section{Gráfica 3}

Tasa de delitos $v$ la salud e incidencia de la pobreza

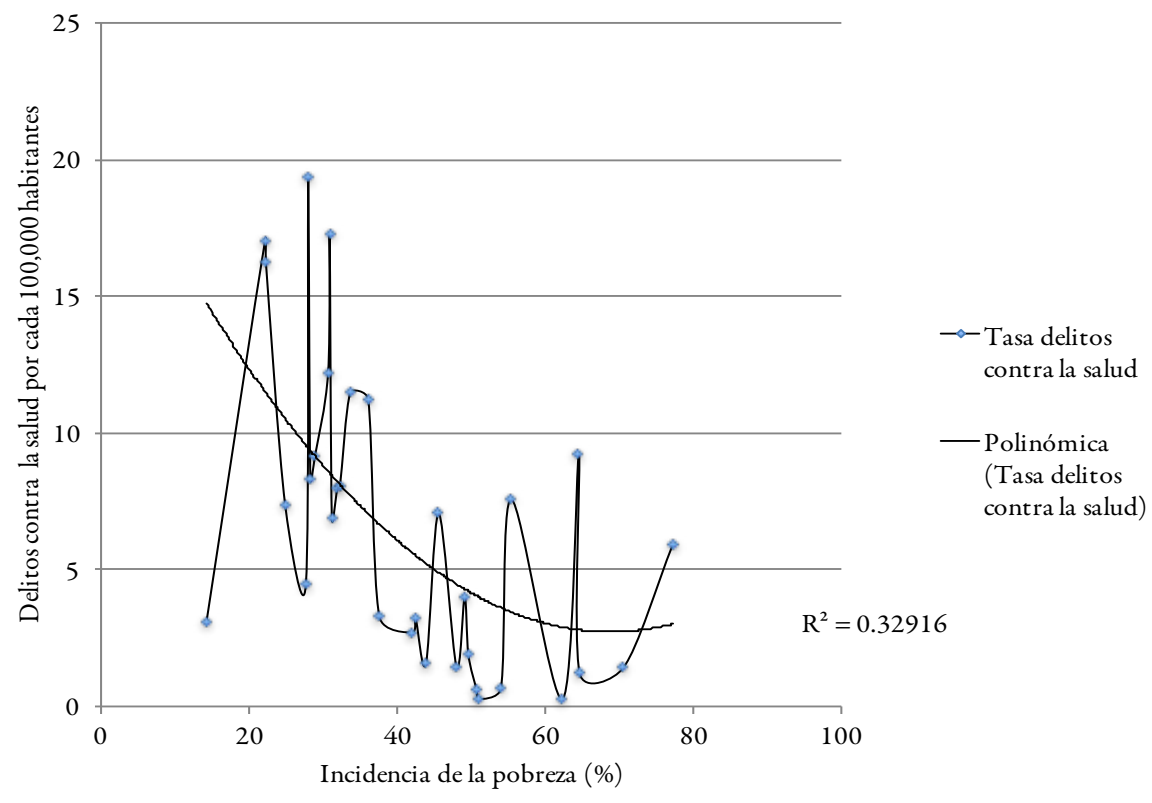

Fuente: Coneval, 2017 y SESNSP, 2018. 


\section{Cuadro 3}

Correlación entre incidencia de la pobreza y Tasa de delitos contra la salud

\begin{tabular}{llll}
\hline Correlaciones & & & \\
\hline & & $\begin{array}{l}\text { Incidencia de } \\
\text { la pobreza }\end{array}$ & $\begin{array}{l}\text { Tasa de delitos } \\
\text { contra salud }\end{array}$ \\
\hline Incidencia de la pobreza & Correlación de Pearson & 1 & $-.540^{* *}$ \\
\hline & Sig. (2-colas) & & 0.001 \\
\hline Tasa de delitos contra salud & Correlación de Pearson & $-.540^{* *}$ & 1 \\
\hline & Sig. (2-colas) & 0.001 & \\
\hline
\end{tabular}

Fuente: Elaboración propia con datos de Coneval, 2017 y SESNSP, 2018.

Henio Gonzalo Millán-Valenzuela. Doctor en Ciencias Sociales y Políticas por la Universidad Iberoamericana; Maestro en Economía por el CIDE y Licenciado en Historia por la UAM-Iztapalapa. Es miembro del Sistema Nacional de Investigadores, nivel 3. En 2014, recibió el Premio de Ciencia y Tecnología otorgado por el Consejo Mexiquense de Ciencia y Tecnología. Desde 1995 es investigador de El Colegio Mexiquense. Líneas de investigación: democracia e instituciones, y pobreza y desarrollo. Publicaciones recientes: Millán-Valenzuela, Henio Gonzalo (2018), “Trampas de la pobreza en México: ¿economía o política?”, en Intersticios Sociales, vol. 8, núm. 15, México: El Colegio de Jalisco, A.C.; Millán-Valenzuela, Henio Gonzalo (2018), “Trabajo y vulnerabilidad hacia la pobreza”, en Porras, Iván, Fabián, Leodegario y Noriega, Fernando [coords.], El mercado de trabajo: visiones alternativas, México: Universidad Autónoma “Benito Juárez” de Oaxaca.

Eduardo Pérez-Archundia. Doctor en Ciencias Sociales y Políticas, profesor investigador del Instituto Superior de Ciencias de la Educación del Estado de México y representante del Cuerpo Académico "Miradas y actores de la convivencia escolar". Líneas de investigación: violencia en las escuelas e inclusión escolar. Publicaciones recientes: Pérez-Archundia, Eduardo y Guerrero, Diana (2016), "La inclusión armónica desde la educación para la paz y la planeación de la convivencia”, en Revista Ra Ximhai, vol. 12, núm. 3, enero-junio, México: Universidad Autónoma Indígena de México; PérezArchundia, Eduardo y Gutiérrez, David (2016), "El conflicto en las instituciones escolares”, en Revista Ra Ximhai, vol. 12, núm. 3, enero-junio, México: Universidad Autónoma Indígena de México. 